TRABAJOS ORIGINALES

Rev Obstet Ginecol Venez. 2020; 80 (4):322-331

https://doi.org/10.51288/00800409

\title{
Asociación entre infección por VPH, presencia de lesiones intraepiteliales en cuello uterino y factores de riesgo.
}

\author{
Dra. Ledyz Cuesta Herrera, ${ }^{1}$ Dr. Hugo Alexander Torres Mantilla, ${ }^{2}$ Msc. Militza Quintero Vega, ${ }^{3}$ \\ Dr. Rafael Borges Peña, ${ }^{4}$ Dr. Jhon Fredy Cruz Gómez. ${ }^{5}$
}

\section{RESUMEN}

\begin{abstract}
Objetivo: Asociar los factores de riesgo, la presencia de lesiones intraepiteliales y la infección por virus del papiloma humano.

Métodos: Estudio transversal con 1639 mujeres del municipio Santos Marquina, Mérida, Venezuela. Se realizaron citologías cervicouterinas y colposcopia, detección y tipificación de virus del papiloma humano mediante reacción en cadena de polimerasa y encuestas.

Resultados: Se encontró que 477 mujeres $(31,8 \%)$ presentaron infección por virus del papiloma humano y 82 $(5,6 \%)$ tuvieron anormalidades en la citología cervicouterina. Dentro de los casos donde se realizó tipificación del virus del papiloma humano, 135 (42\%) corresponden a tipos de bajo riesgo, mientras que 177 (55\%) a tipos de alto riesgo. Hubo mayor proporción de citologías anormales en los casos con virus del papiloma humano de alto riesgo con 21 casos (13,4\%) en comparación con virus del papiloma humano de bajo riesgo con 9 casos $(6,4 \%)$. El número de compañeros sexuales mayor que $1(O R=2,303 ; p=0,001)$ y el antecedente de alguna gestación $(O R=3,283 ; p=0,036)$ fueron significativamente asociados de forma independiente con la presencia de citología anormal. El número de compañeros sexuales mayor que 1 (OR $=1,304 ; p=0,026)$, la zona de residencia rural $(O R=1,957 ; p<0,001)$ y la edad menor de 35 años $(O R=1,397 ; p=0,003)$ fueron significativamente asociados de forma independiente con la presencia de infección por virus del papiloma humano.

Conclusión: El tipo de virus del papiloma humano y otros factores de riesgo tienen un papel importante en la aparición de lesiones cervicouterinas.
\end{abstract}

Palabras clave: Lesiones escamosas intraepiteliales del cuello uterino, Virus del papiloma humano, Citología cervicouterina, Factores de riesgo.

\section{SUMMARY}

Objective: To establish associations between risk factors and the presence of intraepithelial lesions and human papillomavirus infection.

Methods: Cross-sectional study with 1639 from the Santos Marquina municipality, Mérida, Venezuela. Cervical cytology and colposcopy, human papillomavirus detection and genotyping were analyzed using PCR and surveys to measure risk factors.

Results: 477 women (31.8\%) had human papillomavirus infection and 82 women (5.6\%) had abnormalities in cervical cytology. Among the cases where human papillomavirus genotyping was performed, 135 (42\%) correspond to lowrisk types, while 177 (55\%) correspond to high-risk types. A higher proportion of abnormal cytologies was found in cases with high-risk human papillomavirus with 21 cases (13.4\%) compared to low-risk human papillomavirus with 9 cases $(6.4 \%)$. The number of lifetime sexual partners greater than $1(O R=2,303 ; p=0.001)$ and the history of pregnancy $(O R=3,283 ; p=0.036)$ were significant independently associated with the presence of abnormal cytology. While the number of lifetime sexual partners greater than $1(O R=1.304 ; p=0.026)$, the residence in rural area $(O R=1.957 ; p<0.001)$ and the age under 35 years $(O R=1,397 ; p=0.003)$ were significant independently associated with the presence of human papillomavirus infection.

Conclusion: The type of human papillomavirus and other risk factors play an important role in the appearance of cervical intraepithelial lesions.

Keywords: Squamous intraepithelial lesions of the cervix, Human papillomavirus, Papanicolaou Test, Risk factors.

\begin{abstract}
${ }^{1}$ Estudiante de Doctorado en Modelamiento Matemático Aplicado, Línea de investigación Análisis Epidemiológico, Facultad de Ciencias Básicas, Universidad Católica del Maule. Talca. Chile. ${ }^{2}$ Médico y Cirujano. Magister Scientiae en Estadística. Profesor del Departamento de Matemáticas-Física, Facultad de Ciencias Exactas, Naturales y Agropecuarias, Universidad de Santander. Bucaramanga. Colombia. ${ }^{3}$ Magister Scientiae en Biología Molecular. Profesora categoría agregado a dedicación exclusiva. Departamento de Biología, Laboratorio de Biología y
\end{abstract}

Medicina Experimental, Facultad de Ciencias, Universidad de Los Andes. Mérida. Venezuela. ${ }^{4}$ Candidato a Doctor en Salud Pública, mención Bioestadística, Universidad Central de Venezuela, Caracas, Venezuela. Profesor Titular a dedicación exclusiva, Escuela de Estadística, Universidad de Los Andes, Mérida, Venezuela. ${ }^{5}$ Doctor en Biología Molecular. Profesor titular a dedicación exclusiva, Departamento de Biología, Laboratorio de Biología y Medicina Experimental, Facultad de Ciencias, Universidad de Los Andes. Mérida. Venezuela. 


\section{INTRODUCCIÓN}

El virus del papiloma humano (VPH) representa una de las infecciones de transmisión sexual más común, no obstante, es todavía poco conocida. La familia de VPH cuenta con más de 150 tipos virales que, en relación con su patogenia oncológica, se clasifican en tipos de alto y bajo riesgo oncológico; el paradigma de los primeros lo constituyen el VPH 16 y 18 y el de los segundos el VPH 6 y 11 (1).

La infección por papilomavirus ocurre a través de abrasiones en el epitelio, que exponen las células de la capa basal a la entrada de las partículas virales. Una vez en el interior, el ciclo del virus está íntimamente unido al programa de diferenciación de las células y aprovechando la maquinaria celular se replica y se propaga (2).

Desde hace relativamente poco se conoce con cierto detalle el virus del papiloma humano, a pesar de que ha acompañado a los seres humanos desde la antigüedad (3). Fueron necesarios muchos progresos en el campo de la biología molecular para conseguir el grado de conocimiento alcanzado y la aplicación de nuevas técnicas diagnósticas que a su vez han ayudado a dilucidar su comportamiento epidemiológico; históricamente asociado con la aparición de verrugas contagiosas, hoy en día la enfermedad asociada más importante es el cáncer de cuello uterino. No solo se asocia con el cáncer de cuello uterino, adicionalmente, más del $93 \%$ de las pacientes con cáncer de cuello uterino presentan evidencia de ADN viral en el epitelio afectado (4). La determinación de la presencia de algún tipo de VPH de alto riesgo permite orientar de una mejor manera el tratamiento y seguimiento posterior.

El cáncer de cuello uterino es una causa frecuente de muerte predominante en países en vías de desarrollo (5). La reducción en su incidencia y su mortalidad ha sido atribuible al éxito persistente de las estrategias de prevención, tamizaje y tratamiento precoz implementadas desde hace varias décadas en los países más desarrollados. El eje fundamental de dichas estrategias subyace en el papel de la citología cervicouterina llamada también test de Papanicolaou. Esta herramienta aplicada de forma correcta, repetida y sistemática permite con aceptable sensibilidad y especificidad, la detección temprana del cáncer de cuello uterino y de lesiones que se consideran de riesgo para la aparición posterior de cáncer (6).

A pesar de que se ha podido establecer la relación causal entre el virus del papiloma humano y la mayoría de los cánceres de cuello uterino, la relación entre el agente y el hospedero determina el riesgo real de progresión de los cambios celulares hacia la malignidad (7). Dentro de esa relación se encuentra la respuesta inmunológica y los mecanismos anticancerígenos, entre otros fenómenos. El tabaquismo, el consumo de hormonas sexuales, la inmunosupresión y la presencia de inflamación relacionada con otros agentes infecciosos en el cuello, son algunos de los factores que han sido postulados como factores de riesgo para lesiones de alto grado y la progresión posterior a cáncer (8).

El objetivo de esta investigación fue hallar asociaciones entre la infección por $\mathrm{VPH}$, con los resultados citológicos y otras variables como factores de riesgo. Para alcanzar los objetivos planteados se realizó un análisis a cada una de las covariables mediante la aplicación de técnicas estadísticas.

\section{MÉTODOS}

El tipo de estudio que se utilizó para abordar la problemática planteada es cuantitativo de corte transversal (9).

Los datos utilizados en la presente investigación fueron provistos por el Laboratorio de Biología y 
Medicina Experimental (LABIOMEX), adscrito al Departamento de Biología de la Facultad de Ciencias, Universidad de los Andes, Mérida, Venezuela. Estos corresponden a una muestra de las mujeres con inicio de vida sexual pertenecientes al Municipio Santos Marquina del estado Mérida que libremente asistieron a una convocatoria de campaña de prevención temprana de cáncer de cuello uterino y firmaron consentimiento informado para participar en el estudio.

Mediante personal entrenado, se les realizó toma de citología cervicouterina y toma de muestra para la detección del virus. Adicionalmente, en los casos residentes en la zona urbana del municipio, se realizó una colposcopia por parte de un ginecólogo debidamente capacitado en toma de biopsias.

Los investigadores aplicaron directamente una encuesta para determinar factores de riesgo tales como: edad, tabaquismo, edad de inicio de vida sexual, número de parejas sexuales, antecedente de gestación y zona de residencia.

Este estudio es conformado por una muestra de 1639 pacientes, de las cuales se tuvieron en cuenta los resultados de la primera vez de consulta de cada una. La detección y tipificación del VPH se llevó a cabo mediante reacción en cadena de polimerasa (PCR). La PCR permite la amplificación de un gen a partir de una única copia presente en la muestra hasta obtener millones mediante la utilización de cebos o primers. Posteriormente, permite la tipificación del virus mediante el uso de sondas más específicas. Se utilizó una modificación del protocolo propuesto por Manos y cols. (10). Las covariables fueron categorizadas como dicotómicas. La citología cervicouterina se clasificó como anormal según la presencia de cambios citológicos premalignos o malignos que corresponden a la presencia de neoplasia intraepitelial (NIC) 1, 2 o 3 , de carcinoma in situ o de células escamosas atípicas de significado incierto (ASCUS) o células glandulares atípicas de significado incierto (AGUS), sin considerar las lesiones inflamatorias aisladas.

No se consiguieron medir todas las variables en la totalidad de la muestra por ende el análisis estadístico se describe en relación con los casos con mediciones válidas de cada variable. Se contemplaron las siguientes medidas de asociación para tablas de contingencia dentro del presente estudio: prueba estadística Jicuadrado de Pearson, prueba de probabilidad exacta de Fisher para tablas 2x2 (para los casos donde no se cumpla con la mínima frecuencia esperada de celda) y la medida de riesgo razón de oportunidades (OR). Para las asociaciones bivariantes significativas se realizó la medición de la asociación mediante una prueba de independencia condicional, controlando alternativamente el efecto de las demás covariables, utilizando una prueba de homogeneidad de los OR siguiendo la metodología de Mantel-Haenszel. Dentro del análisis y procesamiento de la información se eligió un nivel de significancia del $5 \%$. Se utilizó el software estadístico R versión 3.5.0.

\section{RESULTADOS}

En la tabla 1 se resumen las características de la muestra. La edad promedio de las pacientes fue de 36 años $\pm 10,5$ con edades comprendidas entre los 14 y 62 años. El 31,8 \% (477) de las mujeres presentaron infección por VPH detectable en el cuello uterino. Entre aquellos casos donde se identificó el tipo de VPH, el tipo 6 fue el más frecuente encontrándose en 84 casos (26\%). Dentro de los tipos de alto riesgo los más frecuentes fueron los tipos 16 y 18 hallados en 49 (15\%) y $35(11 \%)$ casos respectivamente.

En total 82 casos (5,6\%) fueron reportados con anormalidades en la citología cervicouterina. En la figura 1 se detalla la prevalencia de infección por VPH según los hallazgos citológicos. Entre los casos con citología anormal se documentó la presencia de 
Tabla 1. Descripción de la muestra de casos

\begin{tabular}{|c|c|c|c|c|}
\hline & $\mathrm{N}^{\circ}$ Casos & Frecuencia & $\%$ & Diagnóstico \\
\hline \multirow{2}{*}{ Resultado de citología } & \multirow{2}{*}{1467} & 1385 & 94,4 & Negativo o Normal \\
\hline & & 82 & 5,6 & Anormal \\
\hline \multirow{2}{*}{ Resultado de colposcopia } & \multirow{2}{*}{638} & 560 & 87,8 & Normal \\
\hline & & 78 & 12,2 & Anormal \\
\hline \multirow{2}{*}{$\begin{array}{l}\text { Diagnóstico de } \mathrm{VPH}^{*} \text { por } \\
\text { PCR** }^{* *}\end{array}$} & \multirow{2}{*}{1501} & 477 & 31,8 & Positivo \\
\hline & & 1024 & 68,2 & Negativo \\
\hline \multirow{3}{*}{ Subtipo de VPH* } & \multirow{3}{*}{323} & $\begin{array}{c}135(6,11,81,67,54,70,44 \\
43,61,42)\end{array}$ & 41,8 & Bajo riesgo \\
\hline & & $\begin{array}{c}177(16,18,31,33,56,58,59,66,52 \\
51,26,68,53,39,82,45,35)\end{array}$ & 54,8 & Alto riesgo \\
\hline & & $11(83,84,74,57)$ & 3,4 & $\begin{array}{l}\text { Riesgo sin asignar o } \\
\text { no hallado }\end{array}$ \\
\hline \multirow{2}{*}{ Grupo etario } & \multirow{2}{*}{1588} & 864 & 54,4 & $\begin{array}{c}\text { Menor o igual a } 35 \\
\text { años }\end{array}$ \\
\hline & & 724 & 45,6 & Mayor a 35 años \\
\hline \multirow{2}{*}{$\begin{array}{l}\text { Edad inicio de vida sexual } \\
\text { (rangos) }\end{array}$} & \multirow{2}{*}{1368} & 941 & 68,9 & $\begin{array}{c}\text { Menor o igual a } 18 \\
\text { años }\end{array}$ \\
\hline & & 425 & 31,1 & Mayor a 18 años \\
\hline \multirow{3}{*}{ Compañeros sexuales } & \multirow{3}{*}{1367} & 657 & 48,1 & Uno \\
\hline & & 544 & 39,8 & Entre dos y tres \\
\hline & & 166 & 12,1 & Más de tres \\
\hline \multirow{3}{*}{ Gestaciones } & \multirow{3}{*}{1206} & 158 & 13,1 & Ninguna \\
\hline & & 619 & 51,3 & 1 a 3 \\
\hline & & 429 & 35,6 & Más de 3 \\
\hline \multirow{2}{*}{ Hábito de fumar } & \multirow{2}{*}{1348} & 1157 & 85,8 & No Fuma \\
\hline & & 191 & 14,2 & Si Fuma \\
\hline \multirow{2}{*}{ Zona } & \multirow{2}{*}{1639} & 993 & 60,6 & Zona Rural \\
\hline & & 646 & 39,4 & Zona Centro \\
\hline
\end{tabular}

* Virus de papiloma humano $\quad * *$ Reacción en cadena de polimerasa 


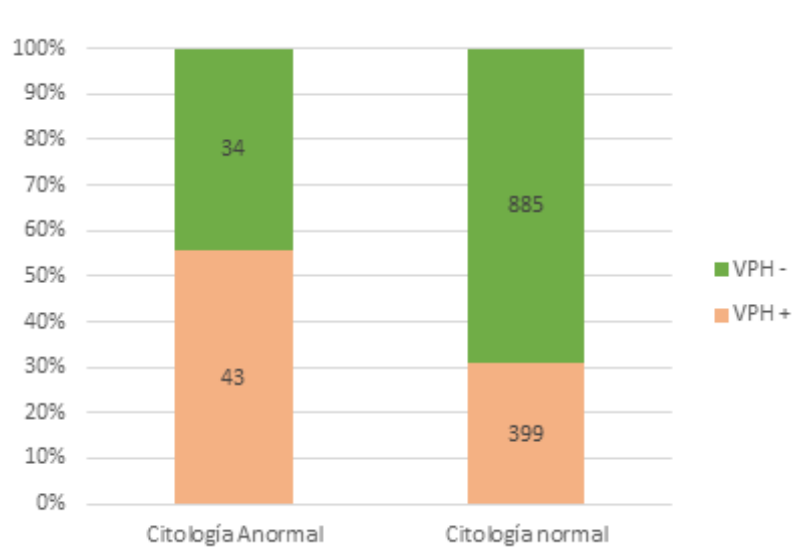

Figura 1. Estado de infección por VPH según la presencia de citología anormal

infección por VPH en 43 de 77 casos (55,8\%), mientras que entre los casos con citología normal la presencia de infección por VPH se encontró en 399 de 1284 casos (31\%). Se realizó colposcopia en 566 mujeres con resultado de citología normal encontrando anormalidad en la colposcopia en 63 casos (11\%). Por el contrario, se realizó colposcopia en 42 casos con citología anormal confirmándose anormalidades en 15 de ellos $(35,7 \%)$. Se encontró una asociación estadísticamente significativa entre la citología y el estado de infección por VPH $(\mathrm{OR}=2,805$, $\mathrm{p}<0,000)$, así mismo entre las variables citología y colposcopia $(\mathrm{OR}=4,436, \mathrm{p}<0,000)$. Al controlar cada una de las covariables alternativamente la prueba de asociación se mantiene estadísticamente significativa.

Dentro de los 312 casos donde se realizó asignación de la tipificación del VPH, 135 (43,3 \%) corresponden a tipos de bajo riesgo, mientras que 177 (56,7 \%) casos corresponden a tipos de alto riesgo $(11,12)$. Entre aquellos casos con infección documentada por VPH de bajo riesgo se encontraron anormalidades en la citología en $9(6,4 \%)$ casos y entre los casos con infección por VPH de alto riesgo se hallaron anormalidades citológicas en 21 casos (13,4\%). Desde otro punto de vista, entre los casos con citología anormal se documentó la presencia de tipo de alto riesgo en $21(70 \%)$ de los 30 casos tipificados, mientras que entre los casos con citología normal esto se encontró en 136 (51\%) de 1 los 268 casos tipificados. Sin embargo, a pesar de la tendencia encontrada esta no fue significativa $(\mathrm{p}=0,054)$.

Dentro de los casos con colposcopia anormal, la presencia de infección por VPH de alto riesgo fue encontrada en $61 \%(14 / 23)$, mientras que en los hallazgos en colposcopia normal fue del $71 \%$ $(62 / 87)$ sin resultar esta asociación significativa.

Las tablas 2 y 3 detallan las pruebas de independencia para las variables: resultado de citología y VPHPCR, ambas dicotomizadas; teniendo en cuenta la estimación puntual de la razón de oportunidades $(\widehat{O R})$, prueba de independencia no condicionada (Fisher, Ji cuadrado), se incluye la frecuencia de casos en cada categoría para las covariables debido a la presencia diferencial de valores perdidos y el estadístico de una prueba de independencia no condicionada con su respectivo valor $\mathrm{p}$.

Las covariables significativamente asociadas con la presencia de citología anormal fueron el número de compañeros sexuales mayor que $1(\widehat{\mathrm{OR}}=2,303$; $\mathrm{p}=0,001)$ y el antecedente de alguna gestación ( $\widehat{\mathrm{OR}}=3,283 ; \mathrm{p}=0,036)$. Se observó que la relación entre la historia de gestaciones y la presencia de citología anormal varía entre mujeres con y sin historia de más de una pareja sexual $(\widehat{\mathrm{OR}}=6,88$ vs $(\widehat{\mathrm{OR}}=1,42)$ sin alcanzar significancia estadística en la prueba de homogeneidad de los OR. En el subgrupo de mujeres sin historia de más de una pareja sexual el efecto de riesgo de las gestaciones previas sobre la citología anormal es no significativo, mientras que en el subgrupo de mujeres con historia de más 


\section{ASOCIACIÓN ENTRE INFECCIÓN POR VPH, PRESENCIA DE LESIONES INTRAEPITELIALES EN CUELLO UTERINO Y FACTORES DE RIESGO}

Tabla 2. Pruebas de independencia entre las covariables y la presencia de citología anormal

\begin{tabular}{|c|c|c|c|c|c|c|c|c|c|c|}
\hline \multicolumn{2}{|l|}{ Factor de riesgo } & $\begin{array}{c}\text { Frecuencia } \\
\text { factor de } \\
\text { riesgo }\end{array}$ & \multicolumn{2}{|c|}{$\begin{array}{l}\text { Citología } \\
\text { anormal }\end{array}$} & \multicolumn{2}{|c|}{$\begin{array}{c}\text { Citología } \\
\text { normal }\end{array}$} & $\begin{array}{c}\text { Razón de } \\
\text { oportunidades } \\
(\widehat{\mathrm{OR}})\end{array}$ & IC $95 \%$ & Ji_2 & $\mathrm{P}$ \\
\hline \multirow{3}{*}{$\begin{array}{l}\text { Número de } \\
\text { compañeros sexuales }\end{array}$} & & & & & & & \multirow{3}{*}{2,303} & \multirow{3}{*}{$1,366-3,882$} & \multirow{3}{*}{10,305} & \multirow{3}{*}{0,001} \\
\hline & $>1$ & 660 & 50 & 7,6 & 610 & 92,4 & & & & \\
\hline & 1 & 611 & 21 & 3,4 & 590 & 96,6 & & & & \\
\hline \multirow{2}{*}{ Inicio de vida sexual } & $\leq 18$ & 874 & 48 & 5,5 & 826 & 94,5 & \multirow{2}{*}{1,058} & \multirow{2}{*}{$0,634-1,766$} & \multirow{2}{*}{0,047} & \multirow{2}{*}{0,895} \\
\hline & $>18$ & 397 & 23 & 5,8 & 374 & 94,2 & & & & \\
\hline \multirow{2}{*}{ Hábito de fumar } & Sí & 178 & 14 & 7,9 & 164 & 92,1 & \multirow{2}{*}{1,602} & \multirow{2}{*}{$0,871-2,946$} & \multirow{2}{*}{2,334} & \multirow{2}{*}{0,152} \\
\hline & No & 1087 & 55 & 5,1 & 1032 & 94,9 & & & & \\
\hline \multirow{2}{*}{ Embarazos previos } & Sí & 981 & 62 & 6,3 & 919 & 93,7 & \multirow{2}{*}{3,283} & \multirow{2}{*}{$1,017-10,59$} & \multirow{2}{*}{4,425} & \multirow{2}{*}{0,036} \\
\hline & No & 149 & 3 & 2,0 & 146 & 98,0 & & & & \\
\hline \multirow{2}{*}{$\begin{array}{l}\text { Zona de residencia } \\
\text { Centro (Tabay) }\end{array}$} & Sí & 545 & 29 & 5,3 & 516 & 94,7 & \multirow{2}{*}{0,921} & \multirow{2}{*}{$0,578-1,468$} & \multirow{2}{*}{0,118} & \multirow{2}{*}{0,814} \\
\hline & No & 922 & 53 & 5,7 & 869 & 94,3 & & & & \\
\hline \multirow{2}{*}{ Edad } & $\leq 35$ & 771 & 40 & 5,2 & 731 & 94,8 & \multirow{2}{*}{1,170} & \multirow{2}{*}{$0,743-1,843$} & 0460 & 0561 \\
\hline & $>35$ & 648 & 39 & 6,0 & 609 & 94,0 & & & 0,402 & 0,501 \\
\hline
\end{tabular}

Tabla 3. Pruebas de independencia entre las covariables y la presencia de infección por VPH

\begin{tabular}{|c|c|c|c|c|c|c|c|c|c|c|}
\hline \multirow[t]{2}{*}{ Factor de riesgo } & & \multirow{2}{*}{$\begin{array}{l}\text { Frecuencia } \\
\text { factor de } \\
\text { riesgo }\end{array}$} & \multicolumn{2}{|c|}{$\begin{array}{l}\text { VPH-PCR } \\
\text { positivo }\end{array}$} & \multicolumn{2}{|c|}{$\begin{array}{c}\text { VPH-PCR } \\
\text { negativo }\end{array}$} & \multirow{2}{*}{$\begin{array}{c}\text { Razón de } \\
\text { oportunidades } \\
(\widehat{\mathrm{OR}})\end{array}$} & \multirow[t]{2}{*}{ IC $95 \%$} & \multirow[t]{2}{*}{ Ji_2 } & \multirow[t]{2}{*}{$\mathrm{P}$} \\
\hline & & & $\mathrm{n}$ & $\%$ & $\mathrm{n}$ & $\%$ & & & & \\
\hline \multirow{2}{*}{$\begin{array}{l}\text { Número de } \\
\text { compañeros sexuales }\end{array}$} & $>1$ & 622 & 240 & 36,1 & 425 & 63,9 & \multirow{2}{*}{1,304} & \multirow{2}{*}{$1,033-1,646$} & \multirow{2}{*}{4,981} & \multirow{2}{*}{0,026} \\
\hline & 1 & 665 & 188 & 30,2 & 434 & 69,8 & & & & \\
\hline \multirow{2}{*}{ Inicio de vida sexual } & $\leq 18$ & 893 & 309 & 34,6 & 584 & 65,4 & \multirow{2}{*}{0,828} & \multirow{2}{*}{$0,641-1,068$} & \multirow{2}{*}{2,114} & \multirow{2}{*}{0,158} \\
\hline & $>18$ & 394 & 120 & 30,5 & 274 & 69,5 & & & & \\
\hline \multirow{2}{*}{ Hábito de fumar } & Sí & 182 & 61 & 33,5 & 121 & 66,5 & \multirow{2}{*}{0,989} & \multirow{2}{*}{$0,709-1,379$} & \multirow{2}{*}{0,004} & \multirow{2}{*}{0,948} \\
\hline & No & 1087 & 367 & 33,8 & 720 & 66,2 & & & & \\
\hline \multirow{2}{*}{ Embarazos previos } & Sí & 997 & 332 & 33,3 & 665 & 66,7 & \multirow{2}{*}{0,998} & \multirow{2}{*}{$0,696-1,433$} & \multirow{2}{*}{0} & \multirow[b]{2}{*}{1} \\
\hline & No & 153 & 51 & 33,3 & 102 & 66,7 & & & & \\
\hline \multirow{2}{*}{$\begin{array}{l}\text { Zona de residencia } \\
\text { Centro (Tabay) }\end{array}$} & Sí & 563 & 130 & 23,1 & 433 & 76,9 & \multirow{2}{*}{0,511} & \multirow{2}{*}{$0,404-0,648$} & \multirow{2}{*}{31,37} & \multirow{2}{*}{0,000} \\
\hline & No & 938 & 347 & 37,0 & 591 & 63,0 & & & & \\
\hline \multirow{2}{*}{ Edad } & $\leq 35$ & 781 & 275 & 35,2 & 506 & 64,8 & \multirow{2}{*}{0,716} & \multirow{2}{*}{$0,572-0,894$} & 8672 & 0002 \\
\hline & $>35$ & 675 & 189 & 28,0 & 486 & 72,0 & & & $0,0 / 2$ & J \\
\hline
\end{tabular}


de una pareja sexual dicho efecto es significativo a un nivel del $5 \%(\mathrm{p}=0,032)$.

En el subgrupo de pacientes sin infección por VPH existe una tendencia no significativa a una mayor frecuencia relativa de citologías anormales en mujeres mayores de 35 años y en mujeres que manifestaron tener el hábito de fumar. En contraste, las covariables significativamente asociadas con la presencia de infección por VPH fueron el número de compañeros sexuales mayor que $1(\widehat{\mathrm{OR}}=1,304$; $\mathrm{p}=0,026)$, la zona de residencia rural $(\widehat{\mathrm{OR}}=1,957$; $\mathrm{p}<0,001)$ y la edad menor de 35 años $(\widehat{O R}=1,397$; $\mathrm{p}=0,003)$. No se modifica la asociación entre las variables al controlar a las demás covariables.

Se evidencia un mayor riesgo significativo de presentar una citología anormal entre las pacientes con historia de alguna gestación ( $\widehat{\mathrm{OR}}$ $=3,283, \mathrm{p}=0,036)$ y con historia de más de una pareja sexual $(\widehat{\mathrm{OR}}=2,303, \mathrm{p}=0,001)$. Existe una asociación estadísticamente significativa independiente a las demás variables entre la zona de procedencia de las mujeres y la presencia de VPH ( $\widehat{\mathrm{OR}}=0,511, \mathrm{p}<0,001)$. Se evidencia un mayor riesgo significativo de presentar infección por VPH en menores de 35 años en comparación con mujeres mayores a esta edad $(\widehat{\mathrm{OR}}=0,716, \mathrm{p}<0,003)$ el cual se mantiene al controlar las demás variables. Se halla una asociación significativa entre la presencia de infección por VPH y el antecedente de más de una pareja sexual que se mantiene tras el control de las demás covariables $(\widehat{\mathrm{OR}}=1,304, \mathrm{p}=0,026)$.

En la tabla 4 se presentan los resultados de las pruebas de independencia entre covariables y los OR correspondientes. Se destaca la asociación entre tabaquismo y el antecedente de múltiples parejas sexuales $(\widehat{\mathrm{OR}}=2,394)$, grupo etario $\mathrm{y}$ antecedente de gestación $(\widehat{\mathrm{OR}}=7,693)$, grupo etario y tabaquismo $(\widehat{\mathrm{OR}}=1,799)$.

Tabla 4. Pruebas de independencia entre las covariables*

\begin{tabular}{ccccccc}
\hline OR /p-valor & $\begin{array}{c}\text { Edad } \\
(\leq 35 \text { años })\end{array}$ & $\begin{array}{c}\text { Edad IVS* } \\
(\leq 18 \text { años })\end{array}$ & $\begin{array}{c}\text { NCS** } \\
(1)\end{array}$ & $\begin{array}{c}\text { Gestaciones } \\
(<1 \mathrm{G})\end{array}$ & $\begin{array}{c}\text { Tabaquismo } \\
(\mathrm{NO})\end{array}$ & $\begin{array}{c}\text { Zona } \\
(\text { Rural })\end{array}$ \\
\hline $\begin{array}{c}\text { Edad } \\
(\leq 35 \text { años })\end{array}$ & & 0,000 & 0,828 & 0,000 & 0,000 & 0,038 \\
$\begin{array}{c}\text { Edad IVS } * \\
(\leq 18 \text { años })\end{array}$ & 1,993 & 0,000 & 0,194 & 0,001 & 0,442 \\
$\quad \begin{array}{c}\text { NCS** } \\
(1)\end{array}$ & 0,974 & 0,416 & & 0,864 & 0,000 & 0,024 \\
$\begin{array}{c}\text { Gestaciones } \\
(<1 \text { G) }\end{array}$ & 7,693 & 0,783 & 0,969 & & 1 & 0,000 \\
$\begin{array}{c}\text { Tabaquismo } \\
(\text { NO })\end{array}$ & 1,799 & 0,523 & 2,394 & 0,994 & & 0,386 \\
$\quad \begin{array}{l}\text { Zona } \\
(\text { Rural })\end{array}$ & 0,802 & 0,902 & 1,313 & 0,421 & 1,164 & \\
\hline
\end{tabular}

Debajo de la diagonal se encuentran los OR estimados; sobre la diagonal se hallan los valores $\mathrm{p}$ de las pruebas de independencia entre las respectivas covariables. * Inicio de vida sexual; ** Número de compañeros sexuales 


\section{ASOCIACIÓN ENTRE INFECCIÓN POR VPH, PRESENCIA DE LESIONES INTRAEPITELIALES \\ EN CUELLO UTERINO Y FACTORES DE RIESGO}

\section{DISCUSIÓN}

El virus del papiloma humano representa un problema multidimensional para la comunidad médica, debido a que las condiciones biológicas, sociales y ambientales influyen en la interacción entre el virus y el hospedero. La incidencia de esta infección se ha incrementado de tal forma que actualmente es la infección viral más frecuente del aparato genital. El VPH se trasmite por contacto sexual, pero no se ha precisado el mecanismo exacto de infección a nivel de la interacción virus-célula del huésped (13).

En este estudio se encontró una prevalencia de infección por VPH del $31 \%$ aproximadamente entre aquellas mujeres con citología normal. En cambio, en las mujeres con citología anormal se documentó la infección en el $56 \%$ de los casos. En un estudio realizado por Contreras y cols. (14) con 74 mujeres en la comunidad de Macapo, estado Cojedes (Venezuela), se encontró una prevalencia de infección estimada del $27 \%$. En cambio, un estudio realizado por Contreras y cols. (15) en una muestra de 236 mujeres en tres ciudades del estado Zulia, Venezuela, se reportó un porcentaje de infección por VPH del $91 \%$ y un porcentaje de anormalidades celulares en la citología del 39,4\%.

La infección por VPH es la más frecuente de las transmitidas sexualmente, debido quizá a los cambios en la conducta sexual. Algunos estudios que se han hecho en poblaciones que acuden a programas de detección a clínicas de atención de enfermedades de trasmisión sexual, notifican prevalencia del $9 \%$ al $13 \%$, en función del tipo de población estudiada, sin embargo, el Instituto Nacional de Salud Pública, en México, a través de su centro de investigaciones de salud, considera conservadoramente la prevalencia citológica de infección por VPH del $10 \%$ de la población femenina $(16,17)$

Vol. 80, No 4, diciembre 2020.
Se estima que la prevalencia de infección por VPH en mujeres con citología normal ronda el 11,7\%, encontrándose en la región de Latinoamérica y el Caribe la segunda prevalencia más alta con una estimación de $16,1 \%$. En el presente estudio, alrededor del $31 \%$ de las mujeres con citología normal demostraron una infección por VPH.

Los hallazgos en la presente investigación muestran que el $32 \%$ de las pacientes obtuvieron prueba molecular positiva para VPH, esta frecuencia es superior a la encontrada en Colombia por Tamayo y cols. (18), quienes evidenciaron un porcentaje de $10,4 \%$ en 1993 y $8,5 \%$ en 1994 , y próxima a la frecuencia establecida en Chile por Ferreccio y cols. (19), quienes señalan que el $14 \%$ de su población analizada presentó positivo para VPH.

Dentro de este estudio la proporción de citologías anormales entre las mujeres con infección por VPH de alto riesgo supera más del doble a esta proporción en mujeres con infección por VPH de bajo riesgo. Esto concuerda con la evidencia disponible en la literatura que demuestra la presencia del virus en casi todos los casos con patología cervical maligna (20), en especial los tipos de alto riesgo (21).

Se documentó una asociación positiva y significativa entre la presencia de una citología anormal y los antecedentes de más de una pareja sexual y de alguna gestación independiente de las demás covariables y del estado de infección por VPH. Por el contrario, no se encontró asociación significativa entre la presencia de una citología anormal y el hábito de fumar.

Un estudio realizado en una muestra estratificada de 126 mujeres en un municipio de Cuba encontró frecuencias relativas significativamente mayores de promiscuidad sexual (historia de tres o más parejas sexuales), multiparidad (historia de más de tres partos) y fumadoras en las mujeres con lesión intraepitelial en comparación con las mujeres sin lesiones (22). 
La precocidad sexual tampoco fue hallada como un factor asociado a la presencia de anormalidades en la citología ni infección por VPH. Esto contrasta con la literatura que muestra que incluso en mujeres que refieren una única pareja sexual el riesgo de infección por VPH aumenta con el paso del tiempo, luego el inicio temprano de relaciones sexuales aumentaría el riesgo de infección por $\operatorname{VPH}(23,24)$.

Se recomienda que futuras investigaciones aplicadas en comunidades en América Latina mejoren la recolección de información y amplíen la muestra para conseguir mayor poder estadístico. Así mismo, se enfatiza en la estandarización y masificación de los métodos de tipificación del VPH para conseguir mayor información de la prevalencia de la infección por cada tipo de VPH.

En conclusión, los resultados de la presente investigación demuestran que existe una fuerte asociación significativa entre los resultados de citología y VPH y entre el grupo etario y VPH. Son factores de riesgo significativamente asociados a citología anormal las mujeres que presentaron historia de más de una pareja sexual y el antecedente de alguna gestación; los factores significativamente asociados a infección por VPH fueron las mujeres menores de 35 años, más de una pareja sexual y la zona de residencia.

Es necesario realizar estudios que involucren la información de seguimiento de los casos a través de las reconsultas posteriores debido a que es posible la existencia de cambios en los hallazgos citológicos o virológicos. Se recomienda tener en cuenta otros enfoques metodológicos, por ejemplo, análisis de datos longitudinales, para el diseño de estudios posteriores.

Los autores expresan su agradecimiento a todas las mujeres que hicieron parte de este estudio, al laboratorio LABIOMEX de la Universidad de Los
Andes, a las doctoras Adriana Rodríguez y Pierina Petrosino, a los médicos cubanos de la misión Barrio adentro Venezuela, a la Lcda. Lilibeth Barreto asistente en el proyecto, a las técnicos Nereyda García y Sofia Cruz y a la memoria del prof. Juan Puig Pons, los cuales hicieron posible la realización de este proyecto.

\section{REFERENCIAS}

1. Bosh FX, Díaz M, de Sanjosé S, Font Marimon R, Castellsagué X, Abril GA et al. Epidemiología de las infecciones por VPH y riesgo de carcinoma cérvico uterino y otros tumores ano-genitales. En: de Sanjosé S y García A, editoras. Virus del Papiloma Humano y cáncer. Epidemiología y prevención. 2007. pp. 31-50.

2. Rodríguez M, García F, Ruiz J. Virus del Papiloma Humano. Situación actual, vacunas y perspectivas de su utilización. Andalucía (España): Junta de Andalucía, Consejería de Salud; 2008.

3. Ciuffo, G. Imnesto positivo con filtrado di verruca volgare. G Ital Mal Veneree. 1907; 48:12-17.

4. Stone KM. Epidemiologic aspects of genital HPV infection. Clin Obstet Gynecol. 1989; 32(1):112-116.

5. Ferlay J, Shin HR, Bray F, Forman D, Mathers C, Parkin DM. Estimates of worldwide burden of cancer in 2008: GLOBOCAN 2008. Int J Cancer. 2010; 127(12):28932917.

6. Screening for squamous cervical cancer: duration of low risk after negative results of cervical cytology and its implication for screening policies. IARC Working Group on evaluation of cervical cancer screening programmes. Br Med J (Clin Res Ed). 1986; 293(6548):659-664.

7. Rosenfeld WD, Vermund SH, Wentz SJ, Burk RD. High prevalence rate of human papillomavirus infection and association with abnormal Papanicolaou smears in sexually active adolescents. Am J Dis Child. 1989; 143(12):1443-1447.

8. Franco EL. Epidemiology of anogenital warts and cancer. Obstet Gynecol Clin North Am. 1996; 23(3):597-623.

9. Álvarez-Hernández G, Delgado-DelaMora J. Diseño de estudios epidemiológicos. I. El estudio transversal: Tomando una fotografía de la salud y la enfermedad. Bol Clin Infant Edo Son. 2015; 32(1):26-34.

10. Manos M, Ting Y, Wright D, Lewis A, Broker T, Wolinsky $\mathrm{S}$, et al. The use of polymerase chain reaction 


\section{ASOCIACIÓN ENTRE INFECCIÓN POR VPH, PRESENCIA DE LESIONES INTRAEPITELIALES EN CUELLO UTERINO Y FACTORES DE RIESGO}

amplification for the detection of genital human papillomaviruses. Cancer Cells. 1989; 7:209-214.

11. Muñoz N. Human papillomavirus and cancer: the epidemiological evidence. J Clin Virol 2000; 19(1-2):15.

12. Carreras R, Xercavins J, Checa M. Virus del papiloma humano y cáncer de cuello de útero. Barcelona: Editorial Panamericana; 2007.

13. Cano GR. Conceptos actuales sobre la infección por virus del papiloma humano. Ginec Obst Mex. 1995; 63:509-513.

14. Contreras L, Correnti M, Ávila M, Guerrero A, León A. Virus papiloma humano (VPH) en contexto ecológico venezolano. (I): diagnóstico citológico y molecular. Salus Online [Internet]. 2008 [consultado $15 \mathrm{de}$ septiembre de 2019]; 12(3): 68-77. Disponible en: https://www.researchgate.net/publication/242415083 Virus_Papiloma_Humano_VPH_en_contexto_ ecologico_venezolano_I_diagnostico_citologico_y_ molecular

15. Contreras A, Urdaneta JR, Baabel N, Maggiolo I. Genotipificación del virus del papiloma humano en mujeres en edad reproductiva del estado Zulia, Venezuela. Vitae Academia Biomédica Digital [Internet]. 2019 [consultado 12 de noviembre de 2019]; 75: [12 páginas]. Disponible en: https://vitae.ucv.ve/ pdfs/VITAE_5878.pdf

16. Vargas VM. Virus del papiloma humano. Aspectos epidemiológicos, carcinogenéticos, diagnósticos y terapéuticos. Ginec Obstet Mex. 1996; 64(9):411-417.

17. Castañeda-Iñiguez MS, Toledo-Cisneros R, GuileraDelgadillo M. Factores de riesgo para cáncer cervicouterino en mujeres de Zacatecas. Salud Pública Mex. 1998; 40(4):330-338.

18. Tamayo L, Valencia M, Escobar S, Pérez L, Villa M, Bedoya A. Tendencia de la infección por el virus del papiloma humano (VPH) en usuarias del Servicio de citología del Laboratorio docente asistencial de la escuela de Bacteriología y Laboratorio Clínico de la Universidad de Antioquia. 1993-1998. Rev Fac Farm. 2001; 42:20-26.
19. Ferreccio C, Prado RB, Luzoro AV, Ampuero SL, Snijders PJ, Meijer CJ, et al. Population-Based prevalence and age distribution of human papillomavirus among women in Santiago, Chile. Cancer Epidemiol Biomarkers Prev. 2004; 13(12):2271-2276.

20. Walboomers JM, Jacobs MV, Manos MM, Bosch FX, Kummer JA, Shah KV, et al. Human papillomavirus is a necessary cause of invasive cervical cancer worldwide. J Pathol. 1999; 189(1):12-19.

21. Khan MJ, Castle PE, Lorincz AT, Wacholder S, Sherman M, Scott DR, et al. The elevated 10-year risk of cervical precancer and cancer in women with human papillomavirus (HPV) type 16 or 18 and the possible utility of type-specific HPV testing in clinical practice. J Natl Cancer Inst. 2005; 97(14):1072-1079.

22. Franco O, Valladares J, Pérez G. Neoplasia intraepitelial cervical en un área de salud. Rev Cubana Obstet Ginecol. 2011; 37(2):193-203.

23. Collins S, Mazloomzadeh S, Winter H, Blomfield P, Bailey A, Young LS, et al. High incidence of cervical human papillomavirus infection in women during their first sexual relationship. BJOG. 2002; 109(1):96-98.

24. Winer RL, Lee SK, Hughes JP, Adam DE, Kiviat NB, Koutsky LA. Genital human papillomavirus infection: Incidence and risk factors in a cohort of female university students. Am J Epidemiol. 2003; 157(3):218226. 